\title{
BANCOS, FAMÍLIAS E ESTADO: REDES E CONEXÕES NO PARANÁ ${ }^{1}$
}

\author{
Leonardo David Micheleto ${ }^{2}$
}

- Enviado em 19/01/2016

- Aprovado em 08/02/2016

O tema geral da pesquisa é a relação entre os grandes bancos, o Estado e as famílias dominantes no Paraná. Pretendemos demonstrar quem são e como atuam os principais agentes destes segmentos, e com quem atuam. Para tanto, estamos realizando um estudo de caso a partir dos bancos Itaú Unibanco e HSBC, desde a década de 1990 até os diais atuais. Esses bancos foram escolhidos pois ambos fizeram aquisições de bancos públicos estaduais no processo de privatizações da década de 1990 e, enquanto o primeiro conta hoje com recordes de lucros e é um dos principais e maiores bancos do país, o segundo teve sua saída anunciada do Brasil em 2015, após um escândalo de vazamento de suas contas na Suiça envolvendo nomes de pessoas públicas brasileiras.

Procuramos entender esse processo pesquisando como esses grupos econômicos se organizam, tanto internamente como externamente, as suas relações com entidades de representação de interesses e com outros grupos econômicos, como influenciam as políticas públicas e fazem os seus interesses se confundirem com os interesses da sociedade, e como se relacionam com a sociedade civil, principalmente no campo econômico, com foco na dívida pública estadual.

Para isso, analisamos uma complexa conjuntura, em suas configurações econômica e política, que abarcam as privatizações e a reestruturação financeira da década de 1990, a crise econômica de 2008 e a atual crise política de 2015. É preciso, ainda, analisar como se inter-

\footnotetext{
${ }^{1}$ Pesquisa de mestrado em andamento sob a orientação do Professor Doutor Ricardo Costa de Oliveira no Programa de Pós-graduação em Sociologia da UFPR.

${ }^{2}$ Graduado em História pela Universidade Federal do Paraná. Membro do Núcleo de Estudos Paranaenses (NEP). Endereço eletrônico: leonardo_micheleto@ hotmail.com
} 
relacionam as conjunturas do sistema financeiro nos níveis nacional e internacional, bem como o enquadramento do Brasil na economia global.

Para entendermos esses processos sociais e políticos, devemos também mapear e analisar as famílias atuantes, a partir da rede de parentesco dos bancos selecionados, estudando suas biografias e conexões com as famílias dominantes locais e agentes de Estado. E também a configuração e atuação das holdings e suas relações com a dívida pública, as privatizações, os órgãos de representação de classe, as organizações político-ideológicas, o Banco Central, o financiamento de campanhas eleitorais, etc.

Os bancos se configuram, hoje, e durante um bom período da história humana, como grupos de grande influência na organização das sociedades. Pode-se dizer que são um dos pilares da economia moderna. Marx já discorria sobre seus mecanismos no século XIX. De lá para cá, muitos foram os cientistas sociais que se dedicaram ao tema, dando conteúdo a numerosos estudos, dentre os quais podemos citar Banqueiros: organização e poder político no Brasil, de Ary Minella, e $O$ Capital Financeiro, de Hilferding. Estudar o papel dos bancos na nossa sociedade é de suma importância, principalmente devido aos recentes exorbitantes lucros obtidos por algumas destas organizações, mesmo em economias em plena recessão. Tais grupos têm acumulado riqueza e poder político, podendo influenciar e ditar as regras na organização do sistema econômico e político dos países.

Atualmente, em sua forma mais moderna, os grandes bancos se estruturam na forma de Grupos Econômicos, que são complexos conjuntos de empresas das mais variadas atividades, comandadas pela lógica do capital financeiro. Sua condição básica é a existência de um núcleo que controla o conjunto de empresas, e tem a capacidade de controlar as decisões estratégicas, através de variados instrumentos de coerção. Os Grupos Econômicos tem como objetivo central a acumulação financeira e ficar no topo da hierarquia, concentrando capital. (PEREIRA, 2006)

É o caso do banco Itaú Unibanco S.A. e do Banco HSBC (Hong Kong and Shanghai Banking Corporation). O Banco Itaú tem sua origem em 1945 em São Paulo, com o Banco Central de Crédito, sob a presidência de Alfredo Egydio de Souza Aranha. No meio de vários processos de fusões, aquisições e mudanças de nome, em 1959 Alfredo convida seu sobrinho Olavo Egydio Setubal para compor a diretoria do banco. Depois de uma assembléia realizada em 1991 é que surgiu a Itaúsa - Investimentos Itaú S.A., empresa holding criada para concentrar as decisões estratégicas do grupo em todos os segmentos financeiros e empresas do setor não-financeiro. (AUGUSTA, 2013). Na década de 1990, adquiriram o Banestado, banco público do estado do 
Paraná, que tinha importante papel no desenvolvimento econômico regional, mas foi utilizado em práticas duvidosas que o deixou à beira da falência. Sua recuperação custou cerca de 5 bilhões e foi privatizado por cerca de 1,6 bilhões. Nesse processo contraímos uma dívida de 5,6 bilhões junto à União, que pagamos até hoje. (FERREIRA, REIS e MACHADO, 2015) Hoje o Itaú é um dos dois maiores bancos do país, passou com segurança pela crise de 2008 e é um dos credores da dívida pública brasileira.

Já o HKSC foi fundado na década de 1860 pelos ingleses em Hong Kong, sua história relacionada com a expansão colonial inglesa do final do século XIX, a partir de seus interesses na China. Depois, incorporou os negócios ingleses no setor de petróleo no Oriente Médio e, a partir dos anos 1980, acompanhou a expansão do capitalismo financeiro internacional, se tornando em 1994 o oitavo maior conglomerado financeiro internacional. (PEREIRA, 2008) No Brasil chegou com relevância em 1997, para assumir o Banco Bamerindus do Brasil S.A, criando a subsidiária HSBC Bank Brasil, que será o nosso objeto de estudo. A herdeira da família Andrade Vieira, família dona do antigo Banco Bamerindus, é Fernanda Vieira Richa, esposa do governador Beto Richa, e secretária de Estado do Trabalho e Desenvolvimento Social. Queremos pesquisar como se dá essa rede política e social depois da venda do Bamerindus, já com o HSBC Bank Brasil, e sua relação com a dívida pública.

Como se vê, as relações de parentesco são centrais para a conformação dessas redes políticas e sociais que formam a classe dominante e são uma das modalidades de reprodução social. A classe dominante é a elite política de poucas famílias que controlam a sociedade, aparentadas entre si, mas com transformações, com entradas e saídas da classe. A gênese local e regional forma o lócus privilegiado da estruturação dessa classe. Sua unidade resulta da diversidade das frações nela reunidas que possuem autonomias específicas e interesses próprios dentro de seu conjunto. É importante o conceito de bloco no poder enquanto unidade de diferentes frações da classe dominante com conflitos internos organizados no Estado. É a fração detentora dos aparelhos de Estado. (OLIVEIRA, 2001)

É nesse sentido então que buscaremos fazer as conexões entre as pessoas que ocupam lugares de poder e influência dentro dos Grupos Econômicos que formam o Itaú Unibanco e o HSBC Brasil, muitos deles descendentes de linhagens familiares onde parte de seus membros ocupa ou já ocupou lugares de poder e influência dentro do Estado. De acordo com Ricardo Oliveira, redes familiares controlam partidos políticos, controlam o centro do poder executivo e formam redes 
atravessando o poder legislativo com parlamentares hereditários, sempre se renovando pelas gerações. (OLIVEIRA, p.13, 2012)

O objetivo geral desse projeto de pesquisa consiste em conhecer quem são e como se organizam os banqueiros, um setor importante da classe dominante. Visa também elucidar aspectos importantes da política paranaense das duas últimas décadas e suas consequências para o panorama social atual. Visa mapear e analisar as redes políticas e sociais que possibilitam os bancos serem um dos mais importantes setores econômicos da sociedade, que concentram riqueza e poder, e influenciam de forma expressiva no poder político, contribuindo para o aumento das desigualdades sociais.

Para alcançar esse objetivo é importante passar pela resolução de algumas questões: observar os bancos como estruturas familiares, portanto mapear as gerações anteriores das famílias dos presidentes; identificar os agentes políticos que facilitaram e facilitam políticas em favor dos bancos e das privatizações; identificar fatores determinantes históricos e atuais que influenciam o Estado em aprovar políticas em favor dos bancos; e realizar um levantamento histórico do surgimento e implementação do neoliberalismo no Brasil e no mundo, e como se deu no Paraná.

Acreditamos que no caso do Itaú Unibanco a estrutura familiar foi fundamental para sua situação atual, assim como para sua boa relação com o governo federal, que reflete no Paraná a sua boa condição. Já o HSBC teve sucesso no Brasil pela sua própria expansão a nível mundial, assim como sua boa relação com parte importante da classe dominante brasileira, como vemos nas contas vazadas do SwissLeaks. Pode ser que encontremos vínculos com políticos do PSDB pela continuidade que pode existir com a família Andrade Vieira e Beto Richa no Paraná. Acreditamos que ambos os bancos se beneficiaram com as compras dos bancos públicos paranaenses, através de relações bem costuradas, o que rendeu suas participações como credores da dívida pública e os alçaram a posições de controladores do mercado, que permitiu que tivessem um certo controle sobre as crises, além de terem agentes em posições privilegiadas em entidades e cargos de Estado. Isso fez com que, mesmo em cenários de crise econômica, os bancos conseguissem bater recordes de lucros em nosso país, e a saída do HSBC só se deveu ao fato de ter saído o escândalo com suas contas na Suíça.

Apesar das crises, os grandes bancos continuam lucrando no Brasil, em grande parte devido ao sistema da dívida pública. O último ciclo da dívida pública começou nos anos 1970, na ditadura militar, com empréstimos a juros flutuantes e ausência de controle de capitais. $\mathrm{O}$ endividamento se dá por emissão de títulos da dívida, não por contratos, e quem os compra são majoritariamente do 
setor financeiro, que tem o capital para tanto, virando dealers, os que têm as condições para dar as cartas no jogo. Ou seja, a dívida pública pauta a política econômica, através de diversos mecanismos: as privatizações, o superávit primário, a Lei de Responsabilidade Fiscal, entre outros. Esses mecanismos fazem do sistema da dívida pública uma bola de neve, em que quanto mais tempo se passa, maior fica a dívida, e para pagar os juros, vão-se cortando gastos sociais. Segundo Maria Lúcia Fatorelli, grande parte desses mecanismos são ilegais. (FATORELLI, 2013) É uma transferência do dinheiro que deveria retornar ao povo e para os bancos. É o principal mecanismo de dominação econômica que sofre o nosso país, e os bancos que são objetos desse estudo participam como credores e até dealers dessa dívida. (PRONZATO, 2014)

Essa dívida é responsável por grande parte da crise política que vive o país atualmente, pois para pagá-la o governo se utiliza de um ajuste fiscal, cortando gastos de políticas públicas e sociais para a população, na forma de saúde, educação, etc., e aumentando impostos para bater as metas do superávit ${ }^{3}$.

Para a realização da pesquisa que propomos, utilizamos principalmente a metodologia de pesquisa de redes sociais. Essa metodologia tem aspecto interdisciplinar e possibilidades de diferentes enfoques teóricos. Para a sociologia, "constitui-se em uma metodologia específica para o estudo das relações sociais. Nesse sentido, não se trata mais de considerar as redes como metáfora 'da estruturação das entidades na sociedade, mas também como método para a descrição e a análise dos padrões de relação nela presentes”. (MINELLA apud MARQUES, 2012, p. 188)

"O conceito de redes sociais está baseado na imagem de indivíduos e instituições vinculados uns aos outros através de relações sociais formais e informais, constituindo uma malha de conexões, uma sofisticada metáfora do tecido social..." (PEREIRA, 2006, p. 14) Essas conexões se tornam bastante complexas, com entrelaçamentos de diretorias e grupos econômicos e são estudadas redes transcorporativas, de relações pessoais (diretorias cruzadas e relações de parentesco), de relações de capital (relações acionárias e de crédito) e de relações comerciais. Além, é claro, de redes políticas e sociais, envolvendo agentes políticos no Estado (por exemplo, no Banco Central), entidades de representação de interesses, organizações político-ideológicas, famílias políticas, entre outros. Esse método foi escolhido pois propicia o desvelamento das relações sociais que explicam o funcionamento da fração da classe dominante que vamos estudar, através de sua conexões, posições que assumem os atores sociais e formas de atuação, além das entidades e organizações que conseguem influenciar. A principal forma de utilizá-lo é na forma de entrecruzamento de 
informações encontradas nas fontes. São muitas as informações que podemos encontrar de forma explícita ou nas entrelinhas, e a partir dessas informações vamos ligando os fatos e conexões de forma sistemática, até chegarmos à configuração da malha social desejada.

Em conjunto com tal metodologia de pesquisa, outras abordagens da realidade empírica serão realizadas, tais como a pesquisa em: jornais, revistas, relatórios financeiros, livros, propagandas, entrevistas, processos judiciais (como CPI do Banestado), publicações na internet, sites das instituições e entidades, colunas sociais, etc. Também utilizaremos biografias como fonte, por oferecer uma riqueza de informações para análise de contexto social, estrutura interna de organizações, etc., e talvez como método se for preciso para construirmos a rede de conexões.

\section{REFERÊNCIAS}

AUGUSTA, Gabriela. Grupos Financeiros no Contexto da Crise (2008): Uma análise dos grupos Bradesco e Itaúsa. Monografia na Universidade Federal de Santa Catarina. Florianópolis, 2013.

FATORELLI, Maria Lúcia. A dívida é um mecanismo financeiro que se autorreproduz e autoalimenta. Rio de Janeiro, 2013. Disponível em: http://www.brasildefato.com.br/node/26016. Acessado em 05/10/15.

MINELLA, Ary. Grupos financeiros no Brasil: em perfil econômico e sociopolítico dos maiores credores privados. Apresentado no V Workshop Empresa, Empresários e Sociedade. Porto Alegre, PUCRS, 2006.

MINELlA, Ary. Análise de Redes Sociais, Classes Sociais e Marxismo. Revista Brasileira de Ciências Sociais - Vol.28, Nº 83. Outubro, 2013.

OLIVEIRA, Ricardo Costa de. Na Teia do Nepotismo. Curitiba - PR, Editora Insight, 2012.

OLIVEIRA, Ricardo Costa de. O Silêncio dos Vencedores. Curitiba - PR, Moinho do Verbo, 2001.

PEREIRA, Thulio. Bancos e Banqueiros, Sociedade e Política: O Bamerindus e José Eduardo de Andrade Vieira (1981 a 1994). Tese de Doutorado na Universidade Federal de Santa Catarina. Florianópolis, 2006.

PRONZATO, Carlos. Dívida Pública Brasileira: A soberania na corda bamba. Rio de Janeiro, 2014. Disponível em: https://www.youtube.com/watch?v=aFzke1cCwUg. Acessado em 05/10/15.

REIS Luiz Fernando, FERREIRA Marco, MACHADO Rafael. A Dívida Pública do Estado do Paraná. Auditoria Cidadã da Dívida. Disponível em: http://www.auditoriacidada.org.br/a-dividapublica-do-estado-do-parana/. Acessado em 05/10/15. 